\title{
Who a Mother with Munchausen's Syndrome by Proxy Who May Have Developed into a Serial Killer: A Case Study
}

\author{
Yasemin Akkoca ${ }^{1}$, Aslı Cepik Kuruoglu ${ }^{2}$, Figen Dagli ${ }^{3}$ \\ ${ }^{1}$ Ankara Training and Research Hospital, Department of Psychiatry, Ankara, Turkey \\ ${ }^{2}$ Gazi University Faculty of Medicine, Department of Psychiatry, Ankara, Turkey \\ ${ }^{3}$ Gazi University Faculty of Medicine, Department of Pediatry, Ankara, Turkey \\ Email address: \\ akkocayasemin@gmail.com (Y. Akkoca), aslikuruoglu@yahoo.com (A. C. Kuruoglu), daglifigen@gmail.com (F. Dagli)
}

\section{To cite this article:}

Yasemin Akkoca, Aslı Cepik Kuruoglu, Figen Dagli. Who a Mother with Munchausen's Syndrome by Proxy Who May Have Developed into a Serial Killer: A Case Study. American Journal of Psychiatry and Neuroscience. Vol. 3, No. 5, 2015, pp. 94-97.

doi: 10.11648/j.ajpn.20150305.13

\begin{abstract}
Factitious disorder imposed on another (FDIA) or Munchausen syndrome by proxy (MSBP) is a kind of child abuse. The perpetrator, usually the mother, intentionally causes an illness or psychological symptoms in the child or invents a history of disease. While, in the literature, some FDIA patients have killed more than one child of their own have been reported, no case in which any patient showing FDIA symptoms turned into a serial killer by killing other people's children. In this paper, we presented a case of FDIA in which the patient may have turned into a serial killer. The case who is 27 month-girl was admitted to Gazi Medical Hospital with the complaint of seizure. The mother was diagnosed as the FDIA in this hospital, two months later, it was learned that the mother had killed her neighbour's child and that she confessed her crime after she was captured. Having examined the history retrospectively, it was discovered that there may also have been other unexpected deaths related with the mother. The suspicious death was lack of evaluated beceause of considered as an accidental event or fate by police. We think that cultural dilemmas could be the reason of delayed explaining of the events. The purpose of this case presentation is to increase the common awareness that FDIA patients could be dangerous for the other children as well as their own ones.
\end{abstract}

Keywords: Munchausen Syndrome by Proxy, Abuse, Serial Killer, Factitious Disorder Imposed on Another

\section{Introduction}

Munchausen's syndrome by proxy was described by Meadow in 1977 as a form of child abuse [1]. Munchausen's by proxy is defined as "factitious disorder imposed on another (FDIA)" in The Diagnostic and Statistical Manual of Mental Disorders, fifth edition (2013). Unlike other definitions, individuals with this disorder produce or fabricate symptoms of illness in another under their care: children, elderly adults, or pets [2]. The child's caregiver, usually the mother, intentionally causes an illness or psychologic symptoms in the child or invents a history of disease [1]. Repeated periods of sickness, death, family breakdown problems, and harm caused to siblings are typically observed in this syndrome [1, 3, 4]. The psychopathology of patients with this condition has not yet been fully understood $[5,6]$. Pediatricians should be suspicious of FDIA when they encounter unknown symptoms or when patients do not respond to any medical treatment because this syndrome cannot be observed with clear indicators or symptoms [6].

It has been noted in the literature that FDIA shows different symptoms and findings. Among the reported examples are intoxication with salt or other medicines, fabricated findings of serious illness like hematuria through adding blood to urine, false epilepsy symptoms, seizures caused by hypoxic conditions, and artificial dermatologic lesions [5, 6].

Although some patients with FDIA have been reported to have killed more than one of their own children, there are no cases in the literature in which any patient with symptoms of FDIA became a serial killer through killing other people's children [7]. The purpose of this case presentation is to increase the common awareness that patients with FDIA could pose a danger to other children, as well as their own.

\section{Case Presentation}

Child "A", a girl aged 27 months, was admitted to Konya Public Hospital with seizures in December 2008. Her mother stated that she had extremity spasms, bruising, and her eyes 
were fixed for 15 minutes every three days. Child A was hospitalized for two weeks and monitored; her electroencephalography (EEG), cranial magnetic resonance imaging report (CMRI), electrocardiography (ECG), echocardiography (ECHO), and metabolic blood values were all normal. Although she had no attacks of epilepsy in hospital, she was prescribed carbamazepine $200 \mathrm{mg}$ due to her history of epilepsy. Child A was referred to Gazi Medical Hospital (GMH) for further research after FDIA was considered because she had not responded to treatment for two months and her parents had displayed suspicious behaviors.

Child A was hospitalized in the pediatric service of GMH. Her physical examination and mental status was good. Her blood tests (e.g. complete blood count, sedimentation, liver, and renal function tests), and the EEG, CMRI, ECG, and ECHO were repeated and each was normal. Although her mother reported that child A had a short seizure in the unit, no seizure was observed by hospital staff, and no seizure was evident on the video EEG during the time that child A was accompanied by her mother over the three days.

The physicians became suspicious of FDIA due to the different stories told by the mother and father regarding child A's suspiciously-deceased sister's similar seizure attacks, and the incompatibility between the symptoms and histories given by the parents. In addition, child A was often left alone at the hospital by the mother while under observation, and the lack of care shown towards herself and child A. Consequently, the Child Protection Department was informed immediately and the child's parents were taken under psychologic observation.

The mother was interviewed by psychiatrists every day for a month. She was aged 22 years, had primary school education, and was a housewife. The mother mentioned that she frequently fought with her husband and described him as impatient and aggressive. She also reported that she had problems with her parents-in-law. She admitted that she sometimes fainted when she became angry or depressed, and that she used a kind of psychiatric medicine which is she couldn't remember its name for a few months. She admitted to hitting her children when she becomes angry, albeit in a 'very slight way,' and acknowledged her anxiety of losing her daughter (child A), as she had with the death of her first daughter. During the 10th conversation, the mother said that another child being kept in the same unit had died; it was the view of the psychiatrist that she appeared to be happy with this news. She was happy because she believed that the deceased child's mother was experiencing her pain and that the dead child's mother had joked with her once about the pain. Although child A's mother was genial during interviews, she became angry after her husband was interviewed, displayed impulse disorders towards the psychiatrist, and a convulsive seizure was observed.

The father was aged 29 years, primary school educated, and had no regular work. He depicted different seizure scenes than the mother had previously described. He said that he had found child A with tightened-hands and lying on the floor as though she had fainted, after he had breathed, she regained consciousness. He reported that his deceased daughter died of intracranial bleeding because her seizures could not be stopped.
Seizures began in child A 3 days after the first child's death. Additionally, the father reported that two days after child A's sister had died, a son of their relatives who was aged 6 years, was found dead in the same bathroom. He also described how another of their friends' children was found unconscious, also in the same bathroom, with bread lodged in his throat. The family believed that there was a "killer genie" in the bathroom. The aforementioned suspicious death was reported as an accidental death to the police; therefore, an in depth inquiry had not been performed by the police. The mother did not mention any of these incidents.

The father emphasized that his wife had developed excessive anger and agitated behaviors since they were married. He reported that she had previously threatened him with a knife and that they did not meet with their relatives because of her jealousy. He also spoke about her violent behaviors against the children, sometimes she had been beaten the children and had once thrown the older child onto the couch. He admitted that although he was often (2-3 times a week) violent towards his wife, she responded in the same way during their fights and that the children had witnessed these incidents.

As a result, through clinical observations and psychometric examinations, the mother was diagnosed as having axis-I conversion disorder, and borderline-antisocial personality disorder at axis II.

The child protection unit agreed that the family should be observed in order to confirm the FDIA diagnosis. Child A was given into the custody of her grandparents and her parents were directed to a psychiatry clinic in the city in which they lived because of the psychopathologic patterns of the mother and the intensely violent family environment. Child A was monitored by the Department of Social Services while she lived with her grandmother and no seizure attack was reported during this period.

\section{Was the mother serial killer?}

Two months later, it was learned that the mother had kidnapped and killed her neighbor's daughter aged 4 years; she had been choked and burned in a stove. The mother was known to have helped in the search for the girl. After being arrested, she confessed that she wanted everyone to taste the same pain she had felt due to her own daughter's death. The woman's physicians became suspicious upon hearing this that she may have been involved in the previously discussed cases, the dead boy, the collapsed boy found at their home with bread in his throat, and the child found dead while staying at the same unit at the hospital. The necessary legal authorities were contacted because of the possibility of a connection between these incidents. The mother was sentenced to a lifetime of imprisonment for killing a child who her neighbor's daughter aged 4 years [8]; however, she was acquitted of the other suspicious deaths because she had not admitted to them and there was a lack of evidence.

\section{Discussion}

In this paper, we presented a case of FDIA in which the patient may have turned into a serial killer. The mother was 
diagnosed as having FDIA and then was found to have killed a child; she was accused of killing her neighbor's daughter and was arrested by the police. There were other suspicious deaths; however, she did not admit to them and there was insufficient evidence for prosecution. Suspicions remain, however, as to whether she whether she was connected with the other deaths.

FDIA is an infrequent type of child abuse, perhaps because it is hard to diagnose. The annual incidence rate for children aged under 16 years is 5 in every 100000 , and in those aged younger than 1 year is 2.8 per 100000 [9]. In general, FDIA is seen to affect children who are under school age and cannot yet speak adequately [10]. Meadow, recorded some risk factors for children based on his own personal experience: children aged under 5 years, incidents of asphyxiation or intoxication, and same symptoms or death previously reported in a sibling [11]. Meadow strongly suggested that physicians be suspicious of this syndrome when they encounter such histories [12].

The rate of death with FDIA is $6 \%$ in all known cases. The true death rate associated with abuse and neglect is unknown because many cases are still underreported [13]. Nevertheless, sibling death issues have been reported in $25 \%$ of cases of FDIA. Moreover, very similar symptoms in siblings have been reported in $61 \%$ of such incidents. It has been recognized that $57 \%$ of the problems such as asphyxiation, unnecessary medicine, or intoxication, the proxy creates or causes the symptoms. Rocha and Devon reported that the general complaints in these cases are anorexia, diarrhea, seizures, and apnea [14]. In our case, the child's sister was reported to have had epilepsy and death was caused by an unexpected intracranial hemorrhage.

Many experts have observed that abusers are the biologic mothers in almost all cases [10,12, 15]. Mercer reported in his cases, like ours, that the mothers were aged 20-25 years and most had emotional and psychologic problems [16]. It is reported that mothers with FDIA very often claim to have had similar symptoms to their children's when they were children $[10,15]$.

Similar to the mother in our case, Makar et al. determined that mothers or caretakers who abuse children are communicative, industrious, and smart to deal with problems, they take care of their children when they are appraised by health teams, and also have knowledge of diseases or some experience in the field of health [17]. However, Meadow described these kinds of patients as those with a low-comprehension capacity, addiction to creating disorders, and alcohol or drug addiction [10]. Meadow also noted that abusers insist on creating symptoms of disorder, even after they are interviewed.

Some cases in which asphyxiation or intoxication have resulted in death have been noted $[9,15]$. In our case, data such as child A's sister, who passed away unexpectedly, and her mother's violent behaviors against child A, suggest that the mother may have abused child A's sister and her death was a possible result. In many cases, there are some diagnostic challenges derived from the lack of adequate indicators or from disregarding the necessary determination progress, lack of identified symptoms, and delayed diagnosis. In our case, although there was a strong suspicion of FDIA throughout the multi-disciplinary determination process, but it could not be confirmed during the first stage. However, it was possible to diagnose FDIA when child A's seizures stopped after she was taken from her mother's care. According to Davis, when family members or professionals such as pediatricians ignore or reject any possibility of abuse, the determination process becomes extended [9]. Abusers are very adept at misleading medical professionals and social service supervisors.

In FDIA cases, physical violence to the child and some physical tests at the hospital give rise to more physical distress and therefore the child suffers more pain and injury [12]. It has been reported that violence by the mother, unnecessary tests, and physical examinations undertaken by physicians are provoked by mothers and therefore these provocations in themselves should be regarded a kind of child abuse [15].

There are insufficient studies on the psycho-social factors that affect family patterns in cases of FDIA. In some incidents, it has been noted that the children's mothers had experienced intense deprivations or/and sexual abuse in their childhood. Although these mothers seem very confident and strong enough to deal with problems, in reality they are very weak, lack confidence, and are dependent on others. These parents appear to participate in activities that provide emotional and social benefits. When fathers are with the family, they keep themselves away from the mother and children both physically and psychologically [18]. The mother usually fears being left by her husband and this interferes with her normal daily activities. It is interesting that relations between the members these families are frequently complicated and their roles have been destroyed [19]. The mother usually has symptoms similar to those the child [20]. In our case, the features of the mother such as her aggressive reflections, resentful personality, and extensive jealousy might be regarded as proof of her low self-confidence. Similarly, the dysfunctional marriage and the mother's convulsive-fainting history are in conformity with the literature.

Even though some sibling death incidents are seen in cases of FDIA, there is no evidence of any incidents of serial or willful murder [7]. In our case, the mother's behavior patterns and manslaughter committed after her daughter's death, and her testimony in which she explained that she killed another child because she wanted to make everyone understand and feel what she had suffered, reflect the ignorance of her possible role in her child's death and the anger and desperation she had experienced. Like in FDIA, it is stated that serial murderers are frequently ignored during their childhood, their parents have a damaged relationship, and they are exposed to sexual abuse more often than other children [21]. In our case, there was with no clear evidence of a pathologic problem in the mother's family. It could be concluded from the interviews conducted with the mother and father that her aggressive behaviors such as extensive jealousy, uncontrolled anger, and other behavioral problems observed since the beginning of the marriage, were indicators of an insalubrious childhood and puberty. Although it is noted that the mother was more often 
defined as having borderline-antisocial personality disorder than FDIA, this scenario is similar with serial killers [22]. Therefore, personality disorder is not a determinative factor for defining individuals as serial killers or patients with FDIA. According to our case, the authors suggest that FDIA would be more accurately determined by pediatricians [23]. Thus the FDIA case was identified owing to the specialist attention of the Child Protection Health Team.

All data and clues should be evaluated in suspicious deaths but there is a great lack of Turkish legal authorities such as police and municipal coroners to examine suspicious events related with children. We do not know whether the police believe in an existence of killer genie as an ordinary people. If the police had examined the event professionally as required the mother would not have been able to take more lives.

In summary, FDIA is very difficult to confirm but it can be lifesaving when diagnosed by a conscientious and diligent health team. In view of the information related to our case, it is understood that such families and facts must be very carefully monitored and followed up. The importance of the observation process and also the attention of the health department over these families must be underscored. A diagnosis alert system that can be accessed immediately by all departments is vital to save lives because the risk of injury to other children is extremely high in cases of FDIA. We think that cultural dilemmas could be the reason for the delayed determination of events. It should always be considered that patients with FDIA could harm other children as well as their own, for any reason.

\section{References}

[1] R. Meadow, "Munchausen syndrome by proxy the hinterland of child abuse," Lancet, vol. 2, no. 8033, pp. 343-345, 1977.

[2] American Psychiatric Association. Diagnostic and Statistical Manual of Mental Disorders, 5th edn. Washington, DC: American Psychiatric Association, 2013.

[3] J. Klepper, A. Heringhaus, C. Wurthmann, and T. Voit, "Expect the unexpected: favourable outcome in Munchausen by Proxy syndrome," Eur J Pediatr, vol. 167, no. 9, pp. 1085-1088, 2008.

[4] H. Schreier, "Munchausen by proxy defined," Pediatrics, vol. 110, no.5, pp. 985-988, 2002.

[5] DM. Hall, "The future of child protection," J R Soc Med, vol. 99, no. 1, pp. 6-9, 2006.

[6] JJ. Stirling, "Beyond Munchausen syndrome by proxy: identification and treatment of child abuse in a medical setting," Pediatrics, vol. 119, no. 5, pp. 1026-1030, 2007.

[7] H. Küçüker, T. Demir and R. Oral, "Pediatric condition falsification (Munchausen syndrome by Proxy) as a continuum of maternal factitious disorder (Munchausen syndrome)," Pediatric Diabetes, vol. 11, no. 8, pp. 572-8, 2010.
[8] The $2^{\text {nd }}$ Felony Court of Konya, 19.9.2009, Cose Number: 2009/55.

[9] P. Davis, R. McClure, K. Rolfe, N. Chessman, S. Pearson, Sibert J, and R. Meadow, "Procedures, placement, and risks of further abuse after Munchausen syndrome by proxy, non-accidental poisoning, and non-accidental suffocation," Arch Dis Child, vol. 78, pp. 217-221, 1998.

[10] MS. Sheridan, "The deceit continues: An uptadete literature review of Munchausen syndrome by proxy," Child Abuse and Neglect, vol. 27, pp. 431-451, 2003.

[11] SR. Meadow, "Management of munchausen syndrome by proxy," Arch Dis Child, vol. 60, pp. 385-393, 1985.

[12] R. Meadow, "Munchausen syndrome by proxy," Biritish Medical Journal, vol. 298, pp. 248-250, 1989.

[13] PG. Schnitzer, SP Gulino, and YT. Yuan, "Advancing public health surveillance to estimate child maltreatment fatalities: Review and recommendations," Child Welfare, vol. 92, no. 2, pp. 77-98, 2013.

[14] D. Rocha, "The phenomena of phantom illness: A discussion of Munchausen syndrome by proxy," Praxis Fall, vol. 4, pp. 52-58, 2004.

[15] O. Polat, H. Dokgöz, "Tüm boyutlarıyla çocuk istismarı. Ankara, Seçkin Yayıncılık, s. 312, 2007.

[16] SO Mercer and JD. Perdue, "Munchausen syndrome by proxy: Social work's role," Social Work, vol. 38, no. 1, pp. 74-81, 1993.

[17] AF. Makar and PJ. Squier, "Munchausen syndrome by proxy: father as a perpetrator," Pediatrics, vol. 85, pp. 370-373, 1990.

[18] DF. Özdemir, SS. Yalçın, A. Zeki, K. Yurdakök, Ş. Özusta, and A. Köse, "Munchausen syndrome by proxy presented as recurrent respiratory arrest and thigh abscess: a case study and overview," The Turkish Journal of Pediatrics, vol. 55, pp. 337-343, 2013.

[19] C. Özbesler and Aİ. Çoban, "Ebeveyn yoluyla Munchausen sendromu olgularında sosyal hizmetin rolü," Aile ve Toplum Eğitim-Kültür ve Araştırma Dergisi, vol.6, no. 22, pp.40-49, 2010.

[20] SA. Haddad, KK. Winer, A. Gupta, S. Chakra barti, P. Noel, and HG Klein,"A puzzling case of anemia," Transfusion, vol. 42, no. 12, pp. 1610-1613, 2002.

[21] W. Berner, "Formen des sadismus [Forms of sadism]," Zeitschrift Psychoanalytische Theorie und Praxis, vol. 12, no.2, pp. 166-182, 1997.

[22] T. Parnell, "Guidelines for identifying cases." In: Parnell T, Day D, eds. Munchausen syndrome by proxy syndrome, Misunderstood child abuse, California: Sage, pp. 47-67, 1998.

[23] C. Bass and D. Glaser, "Factitious disorders 1, Early recognition and management of fabricated or induced illness in children," Lancet vol. 383, pp. 1412-21, 2014. 